\title{
Neurotrophic factor in the treatment of Parkinson disease
}

\author{
Young Mi Yoo, Ph.D., Yong Jung Kim, Ph.D., Uhn Lee, M.D., PH.D., \\ Doo Jin Paik, M.D., Ph.D., Hyun Tae Yoo, M.S., Cheol Wan Park, M.D., Ph.D., \\ Young Bo Kim, M.D., Ph.D., Sang Goo Lee, M.D., Ph.D., Woo Kyung KIM, M.D., Ph.D., \\ and Chan Jong Yoo, M.D., Ph.D.
}

Department of Neurosurgery, Gachon Medical College, Gil Medical Center, Namdong-Ku, Inchon; Department of Biology, College of Natural Science, Inha University, Inchon; and Department of Anatomy and Cell Biology, College of Medicine, Hanyang University, Seoul, South Korea

\begin{abstract}
Object. Parkinson disease (PD) is a well-known degenerative disease resulting in the depletion of dopamine-producing neurons in the pars compacta of the substantia nigra. Adenoviral vector delivery of neurotrophic factors may provide a potential therapy for PD. The authors examined whether glial cell line-derived neurotrophic factor (GDNF) delivered via adenoviral vector (Ad-GDNF) could promote functional recovery in a rat model of PD. Additionally, they examined whether neural precursor cells (NPCs) provide the therapeutic potential of cultured neural cells for cell regeneration and replacement in PD.

Methods. All animals underwent stereotactic injection of 6-hydroxydopamine into the right substantia nigra. Eight weeks later, the rats were tested for apomorphine-induced rotational asymmetry and evaluation of explanted grafts infected with the complementary DNA for GDNF containing NPCs and NPCs alone. In the NPC cultures of embryonic rat striata, the authors found that basic fibroblast growth factor induced the proliferation of stem cells, which give rise to spheres of undifferentiated cells that generate neurons and glia.

Conclusions. In this study the authors found that the reduction of apomorphine-induced rotation was more prominent in parkinsonian rats that received Ad-GDNF-treated grafts containing NPCs (61\%) than in those that received grafts of NPCs alone (16\%).
\end{abstract}

\section{Key Words - Parkinson disease • neural stem cell • glial cell line-derived neurotrophic factor $・$ tyrosine hydroxylase $・$ adenoviral vector}

Parkinson disease is characterized by the progressive loss of dopaminergic neurons and a deficiency of tyrosine hydroxylase, which is necessary for the synthesis of dopamine. Symptoms of PD arise when the remaining number of dopaminergic neurons falls below a critical threshold of $20 \%$ and manifest in a classic motor syndrome with symptoms including bradykinesia, akinesia, tremor, muscular rigidity, and postural instability. ${ }^{10}$

The primary PD treatment strategy involves a pharmacological approach to supply the missing neurotransmitter, dopamine. The precursor to dopamine, L-DOPA is presently the most effective therapy for alleviating PD symptoms. Treatments with L-DOPA, however, are limited in several respects: the inability to achieve site-specific delivery results in unwanted side effects and limits the

Abbreviations used in this paper: Ad-GDNF = adenoviral glial cell line-derived neurotrophic factor; $b F G F=$ basic fibroblast growth factor; $\mathrm{CMV}=$ cytomegalovirus; $\mathrm{CNS}=$ central nervous system; DMEM = Dulbecco modified Eagle's medium; FBS = fetal bovine serum; GFP = green fluorescent protein; $\mathrm{IgG}=$ immunoglobulin G; L-DOPA = L-3,4-dihydroxyphenylalanine; NPC = neural precusor cell; $\mathrm{PBS}=$ phosphate-buffered saline $\mathrm{PD}=$ Parkinson disease; $\mathrm{TH}=$ tyrosine hydroxylase; 6-OHDA = 6-hydroxydopamine. amount of the drug that can be given; unpredictable onmedication/off-medication effects occur as a result of the inability to maintain sustained drug levels in the CNS; and remaining dopamine cells continue to degenerate. ${ }^{8,12}$

One emerging therapeutic option applied in patients with advanced PD is the transplantation of human fetal ventral mesencephalic cells into the striatum. ${ }^{8,19}$ Fetal tissue as a source of dopamine cell replacement, however, has a number of disadvantages, such as possible contamination by microorganisms and viruses; practical problems involving collection, storage, delivery to appropriately large target area, and usual placement in an ectopic location; and possible immune rejection. These issues confine PD-related human fetal tissue transplantation to large medical centers and thereby restrict the widespread implementation of this potentially important therapy. The use of NPCs may overcome many of these problems.

Neural precursor cells have recently been introduced as potential candidates for the replacement of defective cells. It has also been suggested that repopulation of the diseased or injured CNS with such cells may promote both anatomical and behavioral recovery in animal models of neurodegenerative conditions. Multipotent NPCs are immature, uncommitted cells that exist in the developing and even adult nervous system and give rise to the vast array 
of more specialized cells of the mature CNS. ${ }^{5,13,15}$ These cells have been isolated from the embryonic CNS of several species of mammals and shown to retain properties of immature cells such as nestin expression. ${ }^{5,6}$ The NPCs are undifferentiated cells capable of proliferation, self-maintenance, and generation of a large number of progeny. ${ }^{2,5}$ In addition, they are capable of generating new cells in response to injury or disease. ${ }^{5}$ Later in the CNS development, these cells stop dividing and differentiate into the several cell types, including neurons, astrocytes, and oligodendrocytes, which comprise the adult brain. ${ }^{4,5}$

The aim of gene therapy for PD has been to amplify dopamine function and to increase expression of growth factors to rescue dying neurons by using ex vivo modified cells. Gene therapy for PD is focused on the enhancement of brain dopamine levels achieved by either the transplantation of genetically modified autologous cells or the direct viral or synthetic vector-based transfer of genetic material into CNS cells to produce and deliver therapeutic agents to specific brain sites. ${ }^{12}$ An alternative source of donor cells are genetically modified cells engineered to secrete specific neurotrophic factors that replace a lost or defective function. Genetically engineered cells have been transplanted after development of specific CNS lesions and have been shown to ameliorate functional deficits of apomorphine-induced rotational asymmetry. ${ }^{3,8}$

We examined whether NPC-based cell therapy and AdGDNF gene therapy could promote functional recovery in a rat model of PD.

\section{MATERIALS AND METHODS}

\section{Animals and Lesion Surgery}

Forty adult female Sprague-Dawley rats weighing 230 to $250 \mathrm{~g}$ at the start of the experiment were used. All animals underwent unilateral stereotactic injection of 6-OHDA into the right substantia nigra (Fig. 1A and B). Four weeks later, the rats were given a $0.05-\mathrm{mg} / \mathrm{kg}$ intraperitoneal injection of apomorphine and their rotational behavior was monitored in automated rotameter bowls for 30 minutes. ${ }^{8,21}$ Twenty of 40 rats with 6-OHDA-induced lesions satisfied the rotation exercise criteria of the rat PD model. Coordinates of the injection site were 5.3 $\mathrm{mm}$ posterior to bregma, and $2.1 \mathrm{~mm}$ lateral to and 7.6 $\mathrm{mm}$ inferior to dura. Eight micrograms of 6-OHDA (expressed as base), dissolved in $2 \mu \mathrm{l}$ of ice-cold $0.9 \%$ saline containing ascorbic acid $(0.2 \mathrm{mg} / \mathrm{ml})$, was injected at the rate of $1 \mu \mathrm{l} /$ minute and the cannula was left in place 1 minute postinjection.

All rats in which grafts were placed exhibited a minimum mean of 8.5 full body turns/minute on the side contralateral to the lesion. The rotation test was repeated up to three times during 1 month after transplantation.

\section{Neural Precursor Cell Cultures}

Striata were removed from rat embryos (E14) and mechanically dissociated using a fire-polished Pasteur pipette in serum-free medium composed of a 1:1 mixture of DMEM and F-12 nutrient (Gibco, Grand Island, NY). Cells were plated $(106$ cells $/ 15 \mathrm{ml})$ into $75 \mathrm{~cm}^{2}$ tissue culture flasks (Falcon, Franklin Lakes, NJ) without sub-
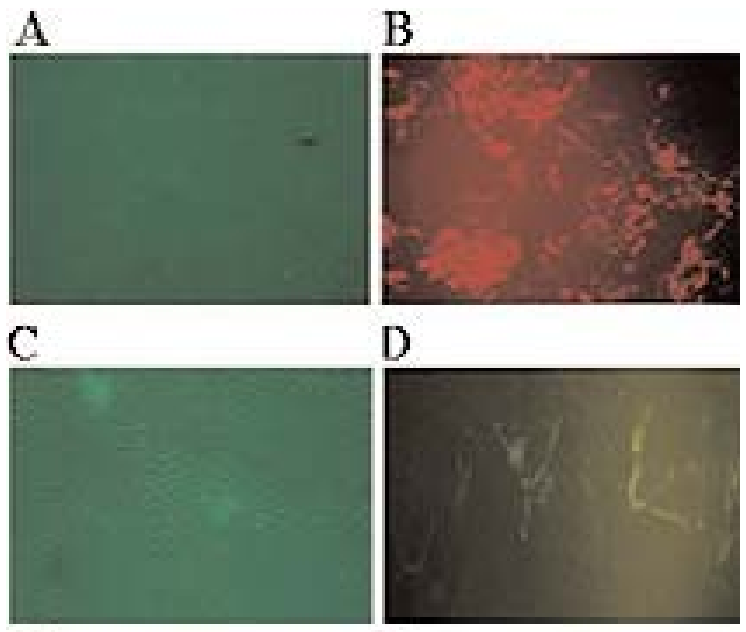

D
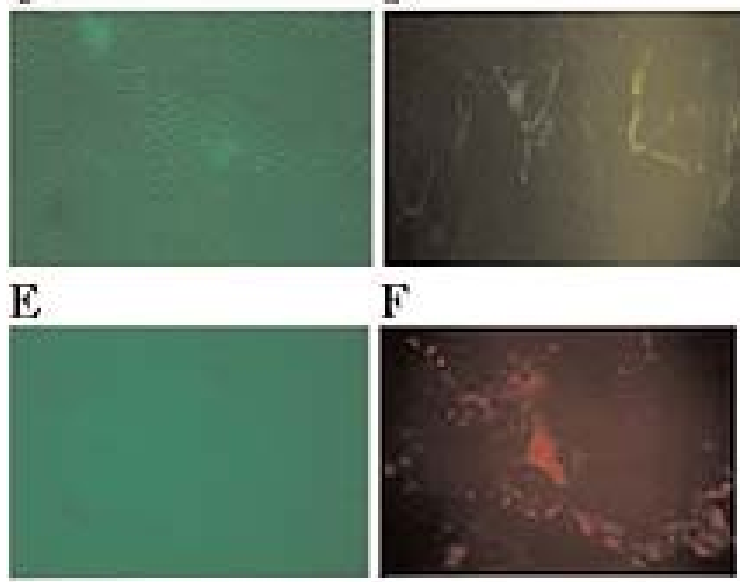

F
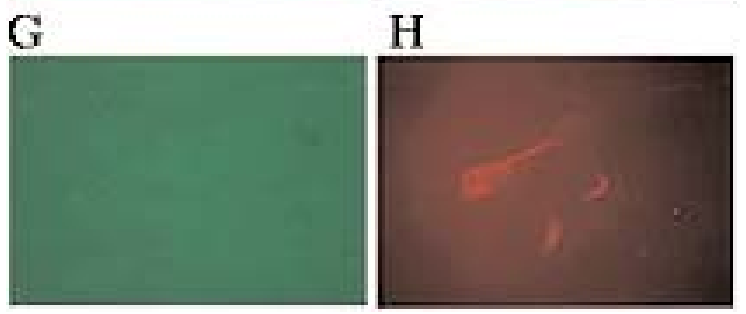

Fig. 1. Photomicrographs showing proliferation of cells isolated from the embryonic rat striata primordium. A: After 2 days in vitro, cells that had undergone cell division were first observed. B: After the cells were immunostained with antibody to nestin, an intermediate filament was found in epithelial stem cells. Differentiated NPCs were fixed and stained with antibodies to glial fibrillary acidic protein $(\mathrm{C}$ and $\mathrm{D})$, neurofilament protein $(\mathrm{E}$ and $\mathrm{F})$, and galactocerebroside $(\mathrm{G}$ and $\mathrm{H})$. Phase $(\mathrm{A}, \mathrm{C}, \mathrm{E}$, and $\mathrm{G})$ and darkfield (B, D, F, and $\mathrm{H})$ images of representative fields showing staining with each antibody are shown. Original magnification $\times 200$.

strate pretreatment. The culture medium was composed of DMEM/F-12 (1:1) supplemented with $20 \mathrm{ng} / \mathrm{ml}$ bFGF. The medium was changed every 5 days. Cell aggregates were dissociated in $0.25 \%$ trypsin and replated in growth medium at 106 cells $/ 15 \mathrm{ml}$.

After 6 days in vitro, the floating sphere-shaped clusters were centrifuged at $600 \mathrm{G}$ for 10 minutes, the bFGF containing medium was removed, and cell aggregates were dissociated in $0.25 \%$ trypsin. Dissociated cells were replated on six-well plates and cultured under the same conditions for mass culture. For plating single cells, a single primary bFGF-generated sphere was collected, mechanically dissociated, and serially diluted as one cell/15- $\mu \mathrm{l}$ aliquot. A 15- $\mu$ l aliquot was added to each well of a 24well plate containing $100 \mu \mathrm{l}$ of bFGF containing medium. Within 24 hours of plating, after most cells had divided, some single cells remained on the plate. Dissociated NPCs 
were plated on poly-L-ornithine-coated glass coverslips in individual wells of 24-well (1-ml/well) culture plates in DMEM/F-12 medium containing 7\% FBS. Coverslips were processed 3 days later for indirect immunocytochemistry.

\section{Immunocytochemical Examination}

Indirect immunocytochemical analysis was performed using single cell-derived spheres and differentiated cells attached to glass coverslips after plating 3 days in vitro. Coverslips were fixed in 4\% paraformaldehyde in PBS ( $\mathrm{pH}$ 7.2) for 30 minutes and followed by three washes in PBS. Primary antiserum was diluted in PBS containing $10 \%$ normal goat serum and incubated with the coverslips for 1 hour at $37^{\circ} \mathrm{C}$. After washing with PBS, cells were incubated with primary antibodies and then fluoresceinlabeled anti-IgG. Coverslips were washed three times in PBS, rinsed with PBS, placed on glass slides, and covered using Fluorsave as the mounting medium. Antibodies to nestin (1:500) and 68-kDa neurofilament proteins (1:400) were used to identify undifferentiated cells and neurons, whereas antibodies were used to identify glial fibrillary acidic protein (1:400) and galactocerebroside (1:500) astrocytes and oligodendrocytes, respectively.

\section{Astrocyte Cultures}

Primary cultures of dissociated cortical astrocytes were obtained from the brains of 1 to 3-day-old neonatal rats. Astrocyte cells were mechanically dissociated using a fire-polished Pasteur pipette in $8 \mathrm{ml}$ of DMEM/F-12 medium supplemented with $7 \% \mathrm{FBS}, 10 \mathrm{mM} \mathrm{Na}_{2} \mathrm{HCO}_{3}$, and were plated on poly-D-lysine-coated $75 \mathrm{~cm}^{3}$ tissue culture plates $(8 \times 105$ /flask $)$.

\section{Adenoviral Vector-Mediated Delivery of GDNF}

The adenovirus vector used in this study has deletions of $E 1$ and $E 3$ genes, which impair the virus' ability to replicate and transform nonpermissive cells. In the vector, pQBI-AdCMV5-GFP was a vector in which autofluorescent protein is combined with the adenovirus expression system. In this transfer vector, the GDNF gene was placed under the control of the modified CMV5 promoter (as in pQBI-AdCMV5), whereas the GFP expression was under the control of a basic CMV promoter. The Ad-CMV5GDNF vector was constructed by inserting the $742 \mathrm{bp}$ HincII/SmaI fragment of GDNF isolated from normal astrocytes between the single BglII and PmeI sites of AdCMV5, downstream of the CMV promoter. To generate a recombinant adenovirus, $5 \mu \mathrm{g}$ of linearized Ad-CMV5GDNF plasmid DNA was cotransfected with $5 \mu \mathrm{g}$ of large ClaI fragment of Ad-CMV5 DNA into the transformedhuman kidney cell line 293 by using FuGENE 6. After a 10-day incubation, clumps of 293 cells routinely detached from monolayers to give the appearance of a plaque. Adenovirus infection characteristically caused cells to form "grape-like" clusters that rounded up and detached. The virus titer was determined by the Tissue Culture Infectious Dose-50 (TCID50) method; ${ }^{11}$ titers of AdCMV5-GDNF $\left(2 \times 10^{5} \mathrm{pfu} / \mu \mathrm{l}\right)$ were then calculated using the Karber formula.

\section{Infection of the Cells}

Astrocytes were grown in DMEM/F-12 medium supplemented with $7 \%$ FBS, $10 \mathrm{mM} \mathrm{Na}_{2} \mathrm{HCO}_{3}$ (Fig.1C). Cultures were maintained on $70 \%$ conditioned medium and kept separate from astrocytes directly infected with recombinant adenovirus for 2 hours. To detect astrocytic GDNF expression, autofluorescent protein was examined under a Zeiss axiovert microscope equipped with an appropriate fluorescence filter (Fig. 1D). Nine weeks after 6OHDA injection, five rats underwent unilateral injection immediately posterior to the striatum with Ad-GDNFinfected astrocyte cells $\left(5 \times 10^{5} / \mu \mathrm{l}\right)$ combined with NPCs $\left(1 \times 10^{6} / \mu l\right)$.

\section{Transplantation of Cells}

Anesthesia was induced by injection of a mixture of ketamine $\mathrm{HCl}(80 \mathrm{mg} / \mathrm{kg})$ and xylazine $(10 \mathrm{mg} / \mathrm{kg})$, and the rats were placed in a stereotaxic frame. Nine weeks after 6-OHDA injection, striata cells or infected cells $(4 \times$ $10^{4}$, suspended in $5 \mathrm{ml} \mathrm{PBS}$ ) were injected into the striatum. The transplants were placed $4.8 \mathrm{~mm}$ lateral to the midline, $2.12 \mathrm{~mm}$ posterior to the bregma, and $6 \mathrm{~mm}$ inferior to the dura. Cell suspensions were slowly injected using a $10-\mu 1$ Hamilton syringe over a 5 -minute period. The needle was left in place another 5 minutes and then slowly withdrawn. Two groups of rats with 6-OHDA-induced lesions received implants of NPCs and Ad-GDNF containing NPCs, respectively. Five of 10 rats in the NPC transplant-treated group were left to serve as an ungrafted lesion control group.

\section{Immunohistochemical Examination}

After 9 weeks, representative selectively lesioned animals fulfilling the aforementioned rotation criteria were killed using an overdose of chloral hydrate and $200 \mathrm{ml}$ of 4\% paraformaldehyde in PBS (pH 7.4). Their brains were rapidly removed and postfixed for 24 hours in the same fixative. Forty-micrometer coronal sections were then cut using cryostat and were processed for immunohistochemistry. Brain sections were rinsed three times in PBS and preincubated in normal goat serum for 30 minutes. The sections were incubated at $4^{\circ} \mathrm{C}$ for 24 hours with rabbit anti-TH serum diluted at 1:1000 in PBS containing 0.3\% Triton X-100 and 1\% normal goat serum. The sections were washed three times for 15 minutes and incubated for 30 minutes in biotinylated secondary antibody (goat antirabbit $\operatorname{IgG})$. The sections were washed and incubated for 30 minutes in vectastain $\mathrm{ABC}$ reagent (Vectastain $\mathrm{ABC}$ Kit; Vector Laboratories, Burlingame, CA). Sections were washed with PBS and developed in diaminobenzidine tetrahydrochloride, washed in tap water, cleared, and mounted using permount. For immunofluorescence, secondary antibody was replaced by $\mathrm{Cy} 3$-conjugated donkey antirabbit IgG (1:200; Jackson Immunoresearch, West Grove, PA) for 3 hours.

\section{RESULTS}

\section{Proliferation and Differentiation of NPCs}

Our findings indicated that bFGF induced the proliferation of single cells derived from the E14 rat striata pri- 
mordium to form a cluster of undifferentiated cells. When E14 striatal cells were cultured in the presence of bFGF and in the absence of poly-L-ornithine, after 6 to 8 days in vitro the bFGF-generated cluster detached from the substrate and floated in suspension. The majority of cells in the proliferating cluster expressed nestin immunoreactivity (Figs. 1A and B and 2A and B), suggesting that they contained intermediate filament protein found in CNS neuroepithelial stem cells. Differentiated cells were then fixed and processed for immunocytochemical examination. Immunocytochemistry showed that NPCs derived from striata primordium differentiated neuron (Fig. 1E and F), astrocytes (Fig. 1C and D), and oligodendrocytes (Fig. $1 \mathrm{G}$ and $\mathrm{H}$ ).
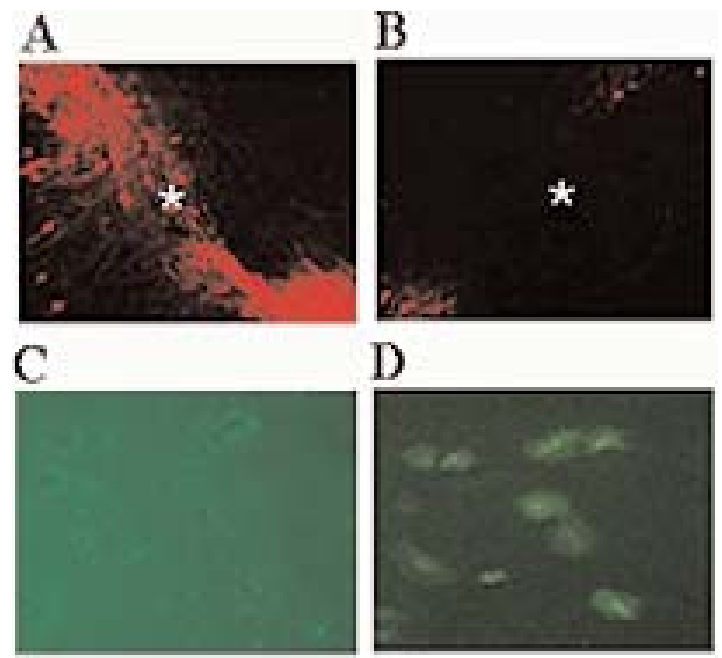

D
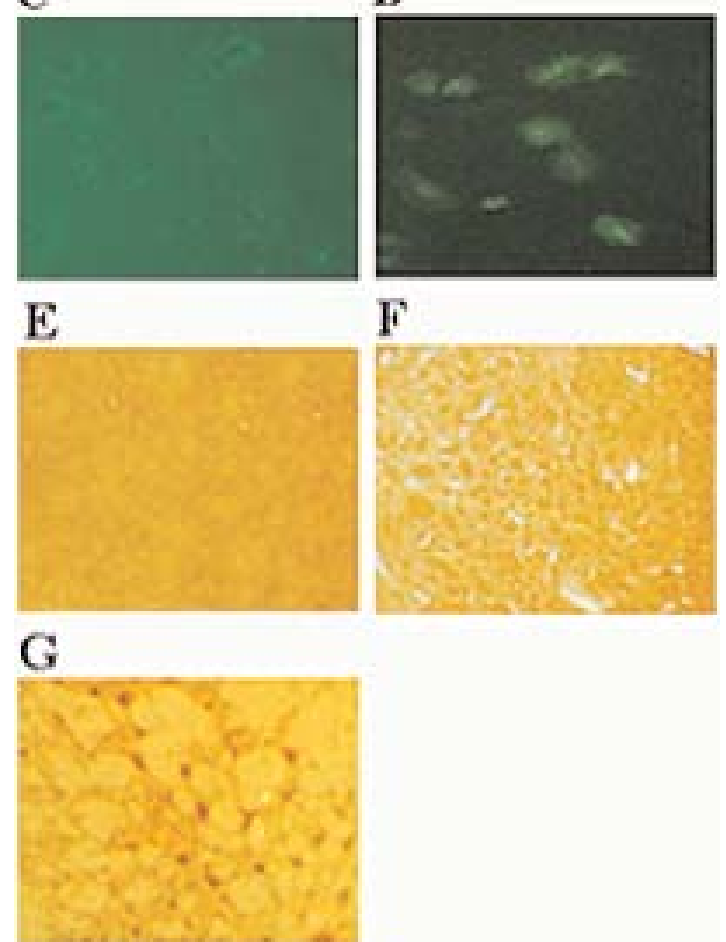

Fig. 2. Photomicrographs showing TH immunostaining on normal side (A) and 6-OHDA-lesioned side (B). The 6-OHDA lesion significantly reduced $\mathrm{TH}$-positive staining in the substantia nigra pars compacta (asterisks in A and B). C: Detection of transgene expression in astrocytes by a recombinant adenovirus containing GFP. D: Gene expression, assayed by GFP, is shown 3 days after infection with a multiplicity of infection of 10. E-G: Photomicrographs of coronal sections through the striatum stain for $\mathrm{TH}$ immunohistochemical stain in a rat from the control group (E), parkinsonian NPC alone graft-treated rats $(\mathrm{F})$, and with Ad-GDNF containing NPCs $(\mathrm{G})$. Original magnification $\times 100$.

\section{Drug-Induced Rotation TH Analysis}

The results of the apomorphine-induced rotational asymmetry tests are summarized in Fig. 3 In the apomorphine rotation test, the Ad-GDNF/NPC graft-treated rats decreased the number of rotations to approximately 3.5 turns/minute, whereas the NPC-grafted animals performed 7.1 turns/minute using the side contralateral to the lesion (Table 1); there was a statistically significant difference between these two groups. Control (Fig. 1E) and NPC-treated (Fig. 1F) rats showed a similar pattern for TH expression. On the other hand, TH immunohistochemistry showed an increase in TH staining in Ad-GDNFtreated group (Fig. 1G) compared with control and the NPC-treated groups.

\section{DISCUSSION}

We have used NPCs, which have the ability to generate new cells in response to injury or disease. Primarily this study demonstrates, through in vitro clonal and population analyses, a mammallian neural stem cell that proliferates in response to an identified growth factor (bFGF) and produces the three principal cell types of the CNS. The bFGF responsive cell is capable of maintaining and expanding itself as a population over extended periods of time, and retains the ability to produce neurons, astrocytes, and oligodendrocytes. In this study, NPCs were initially grown as a polyclonal population first in serum-supplemented and then in serum-free medium containing bFGF.

The establishment and use of stable, engraftable, clonal, and multipotent neural stem cell lines has recently added an exciting new dimension to strategies for cell replacement and gene transfer in the diseased mammallian CNS. ${ }^{2,4,5}$ The standard for isolating neural stem cells in vitro is to dissect free a region of the fetal or adult brain that has been demonstrated to contain dividing cells in vivo-for example, the subventricular zone or the hippocampus in the adult or a larger variety of structures in the developing brain. Usually, the tissue is disaggregated, and the dissociated cells are then exposed to a high concentration of mitogens such as bFGF or epithelial growth factor in either a defined or supplemented medium on a matrix as a substrate for binding. After some proliferation, the cells are either induced to differentiate by withdrawing the mitogens or by exposing the cells to another factor that induces some of the cells to develop into different lineages. Cellular fates are analyzed by staining with antibodies directed against antigens specific for astrocytes, oligodendrocytes, and neurons. Flax, et al., ${ }^{5}$ recently obtained precursor cells from the forebrain, adjacent to the ventricle, in a human fetus at 15 weeks' gestation by using methods similar to those described by Reynolds and Weiss. ${ }^{14}$ These cells were passaged weekly for more than 1 year and thus did not exhibit cellular senescence. After the cells were placed in serum-containing medium, they differentiated into neurons and oligodendrocytes; when they were cocultured with tissue derived from mouse CNS, astrocytes also formed.

In the present study, neural precursor cells were isolated from embryonic Day 14 rat primordium. The NPCs proliferated clones when bFGF was added to the culture medium. Therefore, this responsiveness was chosen for 

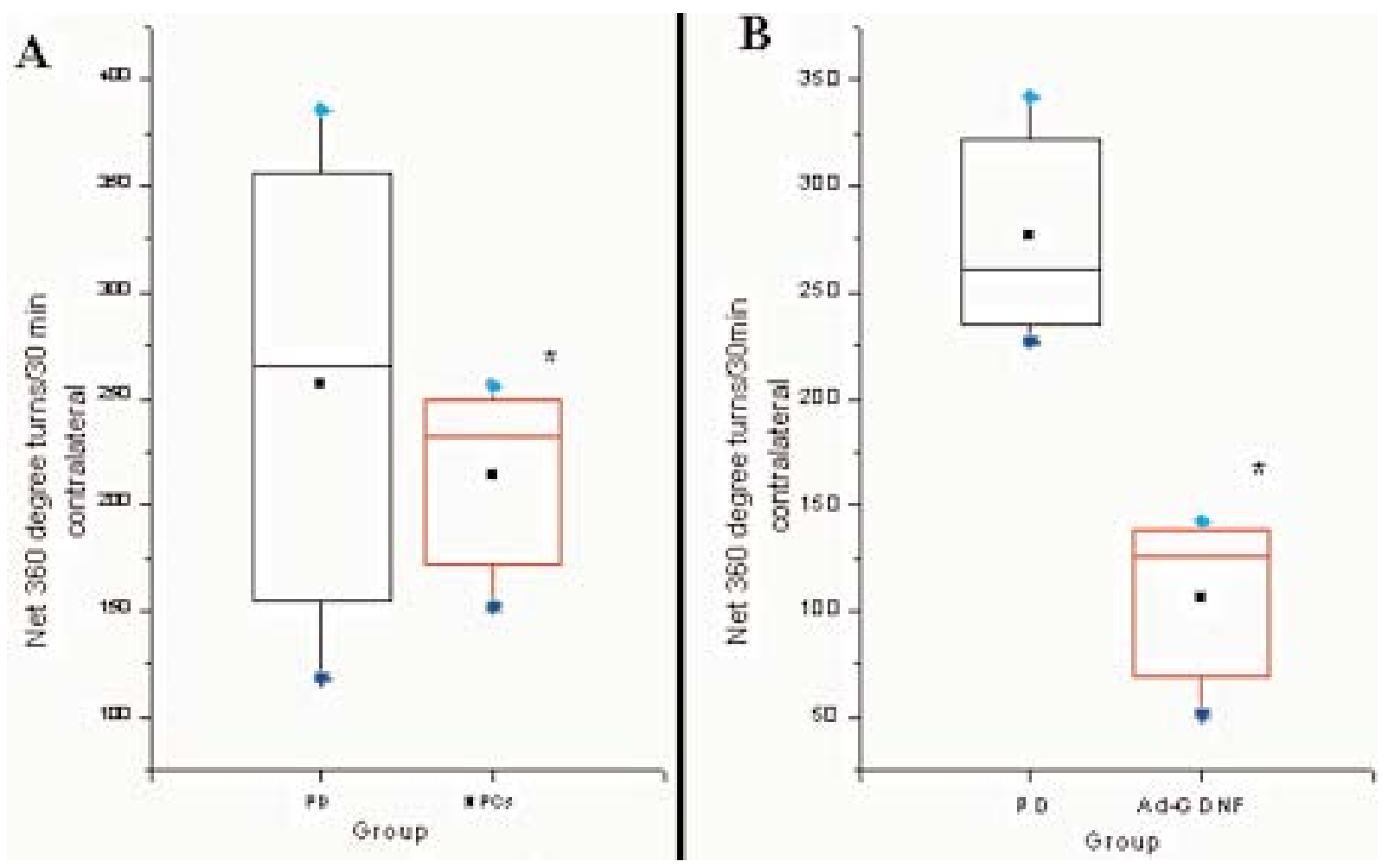

Fig. 3. Graphs demonstrating rotational behavior (mean \pm standard error of the mean of net counter-clockwise fullbody turns/minute over 30 minutes) induced by $0.05 \mathrm{mg} / \mathrm{kg}$ apomorphine in PD and two graft-treated group (*significant difference from pregrafting group $[\mathrm{p}<0.05$, t-test $])$.

both screening and enriching a starting population of stable, dissociated, cultured primary neural precursor cells. Initially NPCs were grown as a polyclonal population first in serum-supplemented and then in serum-free medium containing bFGF. In uncoated dishes and serum-free medium supplemented with bFGF, all clones grew in cultures as clusters that could be passaged weekly for at least 2 months.

It has been reported that bFGF cooperates with other signals in allowing the long-term renewal of both pluripotential embryonic stem cells and $\mathrm{O}-2 \mathrm{~A}$ glial progenitor cells. It has been successfully used to isolate and culture neural stem cells from embryonic mouse cerebral cortex, mesencephalon and telencephalon, embryonic rat striatum, and hippocampus. Additionally, bFGF responsive neural stem cells have been isolated from adult rat hippocampus and adult mouse striatum. Upon in vitro primary culture, these cells readily formed a nestin-positive cluster, indicating the proliferation of undifferentiated cells. In many studies, cells obtained from the fetal brain have grown under similar conditions. ${ }^{17,18}$ Proliferating neural precursor cells also can be obtained from the adult hippocampus and subventricular zone. ${ }^{6}$ Svendsen, et al., ${ }^{18}$ reported that precursor cells isolated from the developing CNS could expand exponentially in culture while retaining the ability to differentiate into neurons and glia. Reynolds and Weiss ${ }^{14}$ discovered a technique for removing cells from the fetal or adult brain, growing them in culture, and subsequently inducing them to differentiate into neurons and glia. We used the method described by Reynolds and Weiss for culture of NPCs. Through primary NPCs, we observed that NPCs could be expanded in vitro in the presence of bFGF but that they stop dividing in serumfree conditions without mitogen or FBS (data not shown). For this reason, in the NPC-alone transplant group little change of rotational asymmetry was shown compared with the control group (Fig. 1E and F). Transplanted NPCs rarely developed to TH-positive neurons in dopamine-depleted striatum. Neurotrophic factors are endogenous soluble proteins that regulate the survival, growth, and morphological plasticity of neurons, in addition to protecting neurons against various insults. Thus, neurotrophic factors that specifically prevent degeneration and increase the functional activity of dopaminergic neurons

TABLE 1

Changes in apomorphine-induced rotational behavior after transplantations*

\begin{tabular}{|c|c|c|c|}
\hline \multirow[b]{3}{*}{ Group (no. of animals) } & \multicolumn{3}{|c|}{ Rotations (turns/30 minutes) } \\
\hline & \multicolumn{2}{|c|}{ Transplantation } & \multirow{2}{*}{$\begin{array}{l}\text { Reduc- } \\
\text { tion } \\
\text { Rate }(\%)\end{array}$} \\
\hline & Pre & Post & \\
\hline NPCs alone (10) & $256.33 \pm 77.48$ & $213.33 \pm 31.43 \dagger$ & 16.78 \\
\hline NPCs + Ad-GDNF (5) & $276.66 \pm 31.10$ & $106.33 \pm 28.04 \dagger$ & 61.57 \\
\hline
\end{tabular}

* Data are provided as means \pm standard error of the mean.

$\dagger$ Significant difference from score demonstrated before transplantation. $(\mathrm{p}<0.05$, t-test). 
are of substantial interest in the development of new therapies for PD.

Several neurotrophic factors, such as brain-derived neurotrophic factor, have shown promise in the rescue of dopaminergic neurons in vitro. Their effectiveness in vivo, however, has been, for the most part, somewhat less promising. ${ }^{19}$ Glial cell line-derived neurotrophic factor has been reported to enhance the survival of midbrain dopaminergic neurons in vivo. ${ }^{3,7}$ It also has been reported to exert protective effects on degenerating dopaminergic neurons in vivo. More recently, GDNF has been shown to promote the survival and neurite extension of cultured dopamine neurons damaged by the neurotoxin 1-methyl4-phenypyridinium. Glial cell line-derived neurotrophic factor is a novel member of the transforming growth factor family and is reported to exhibit trophic factor on embryonic substantia nigra dopaminergic neurons in vitro and possibly in vivo. ${ }^{1,3,7,9,16,19,20}$ It may qualify as a highly specific dopaminergic neurotrophic factor with potential therapeutic benefit in the treatment of PD, a neurodegenerative disorder characterized by the loss of dopaminergic neurons in substantia nigra. For these reasons, it is suggested that GDNF exerts long-lasting trophic effects on dopaminergic neurons in vivo and may be useful as a potential therapeutic agent in individuals suffering from PD. In this study, GDNF has been shown to reverse apomorphine-induced rotation and rescue lesioned dopaminergic neurons. Animals treated with GDNF showed a significant reduction $(>60 \%)$ in the number of rotations, indicating an improvement in nigrostriatal dopaminergic function.

\section{CONCLUSIONS}

Intrastriatal implantation of GDNF-producing astrocytes with NPCs reduced apomorphine-induced rotation. These data suggest that GDNF may be effective at reversing motor deficits at later stages during the evolution of PD.

\section{References}

1. Aubert I, Ridet JL, Gage FH: Regeneration in the adult mammalian CNS: guided by development. Curr Opin Neurobiol 5:625-635, 1995

2. Bain G, Kitchens D, Yao M, et al: Embryonic stem cells express neuronal properties in vitro. Dev Biol 168:342-357, 1995

3. Choi-Lundberg DL, Lin Q, Chang YN, et al: Dopaminergic neurons protected from degeneration by GDNF gene therapy. Science 275:838-841, 1997

4. Craig CG, Tropepe V, Morshead CM, et al: In vivo growth factor expansion of endogenous subependymal neural precursor cell populations in adult mouse brain. J Neurosci 16: 2649-2658, 1996

5. Flax JD, Aurora S, Yang C, et al: Engraftable human neural stem cells respond to developmental cues, replace neurons, and express foreign genes. Nat Biotechnol 16:1033-1039, 1998

6. Gage FH, Coates PW, Palmer TD, et al: Survival and differen- tiation of adult neuronal progenitor cells transplanted to the adult brain. Proc Natl Acad Sci USA 92:11879-11883, 1995

7. Lapchak PA, Gash DM, Jiao S, et al: Glial cell line-derived neurotrophic factor: a novel therapeutic approach to treat motor dysfunction in Parkinson's disease. Exp Neurol 144:29-34, 1997

8. Moffat M, Harmon S, Haycock J, et al: L-Dopa and dopamineproducing gene cassettes for gene therapy approachs to Parkinson's disease. Exp Neurol 144:69-73, 1997

9. Möller JC, Sautter J, Kupsch A: Potential of neurotrophic factors in therapy of Parkinson's disease. J Neural Transm Suppl 48:103-112, 1996

10. Polymeropoulos MH, Higgins JJ, Golbe LI, et al: Mapping of a gene for Parkinson's disease to chromosome 4q21-q23. Science 274:1197-1199, 1996

11. Precious B, Russell WC: Growth, purification and titration of adenoviruses, in Mahy BWJ (ed): Virology: A Practical Approach. Oxford: IRL Press, 1985, pp 193-205

12. Raymon HK, Thode S, Gage FH: Application of ex vivo gene therapy in the treatment of Parkinson's disease. Exp Neurol 144:82-91, 1997

13. Renfranz PJ, Cunningham MG, McKay RD: Region-specific differentiation of the hippocampal stem cell line HiB5 upon implantation into the developing mammalian brain. Cell 66: 713-729, 1991

14. Reynolds BA, Weiss S: Generation of neurons and astrocytes from isolated cells of the adult mammalian central nervous system. Science 255:1707-1710, 1992

15. Snyder EY, Deitcher DL, Walsh C, et al: Multipotent neural cell lines can graft and participate in development of mouse cerebellum. Cell 68:33-51, 1992

16. Springer JE, Mu X, Bergmann LW, et al: Expression of GDNF mRNA in rat and human nervous tissue. Exp Neurol 127: 167-170, 1994

17. Stemple DL, Mahanthappa NK: Neural stem cells are blasting off. Neuron 18:1-4, 1997

18. Svendsen CN, Clarke DJ, Rosser AE, et al: Survival and differentiation of rat and human epidermal growth factor-responsive precursor cells following grafting into the lesioned adult central nervous system. Exp Neurol 137:376-388, 1996

19. Tseng JL, Baetge EE, Zurn AD, et al: GDNF reduces druginduced rotational behavior after medial forebrain bundle transection by a mechanism not involving striatal dopamine. J Neurosci 17:325-333, 1997

20. Yamamoto M, Sobue G, Yamamoto K, et al: Expression of mRNAs for neurotrophic factors (NGF, BDNF, NT-3, and GDNF) and their receptors (p75NGFR, trkA, trkB, and trkC) in the adult human peripheral nervous system and nonneural tissues. Neurochem Res 21:929-938, 1996

21. Ungerstedt U, Arbuthnott GW: Quantitative recording of rotational behavior in rats after 6-hydroxy-dopamine lesions of the nigrostriatal dopamine system. Brain Res 24:485-493, 1970

Manuscript received March 29, 2002.

Accepted in final form May 7, 2003.

This study was supported by a grant of the Korea Health 21 R\&D Project, Ministry of Health and Welfare, Republic of Korea (HMP00-CN-01-0018) to Dr. Lee.

Address reprint requests to: Young Mi Yoo, Ph.D., Department of Neurosurgery, Gachon Medical College, Gil Medical Center, 1198 Kuwel-Dong, Namdong-Ku, Inchon 405-220, South Korea. email:neurobeauty@hanmail.net. 